\title{
Commentary
}

\section{BMP-6 Emerges as a Potential Major Regulator of Fibrosis in the Kidney}

\author{
Robert H. Jenkins and Donald J. Fraser \\ From the Institute of Nephrology, School of Medicine, Cardiff \\ University, Heath Park, Cardiff, United Kingdom
}

Inexorable loss of kidney function in persons with chronic kidney disease (CKD) is a major health burden, leading to renal failure that is predictable but unavoidable despite current therapies. Progression of tubulointerstitial fibrosis is a core determinant of prognosis in CKD. In this sense, CKD falls into the fibro-proliferative disorders, a group of diseases typified by excessive scarring in one or more organs, and which between them take an enormous toll on human health and longevity. ${ }^{1}$

Transforming growth factor $\beta-1$ (TGF- $\beta 1$ ) is the prototypic member of the TGF- $\beta$ family and is widely recognized to be a key determinant of fibro-proliferative diseases. ${ }^{2}$ However, TGF- $\beta 1$ has multiple other roles, acting as a central orchestrator of embryonic development, inflammation and immunity, wound healing, and cancer. The factors governing how cells read TGF- $\beta 1$ signals are thus central to understanding pathology in many contexts. ${ }^{3}$

The TGF- $\beta$ family comprises not just the isoforms of TGF- $\beta$ itself but other cytokines, including the activins, inhibins, and bone morphogenetic proteins (BMPs). Cytokines from the TGF- $\beta$ family elicit their biologic functions by binding to a series of structurally related type I and type II receptors. The activated receptor complex serine-phosphorylates receptor regulated Smad proteins (R-Smads, the intracellular signaling molecules of the TGF- $\beta$ family). Phosphorylated R-Smads form complexes with the co-Smad (Smad 4), accumulate in the nucleus, and alter gene transcription. Combinatorial interactions of type II and type I receptors occur, but the receptorsand R-Smads phosphorylated by them - can be functionally grouped into "TGF- $\beta$-like" and "BMP-like." Smads for TGF- $\beta$ and related ligands are Smads 2 and 3 , whereas for BMP-type ligands the R-Smads are Smads 1 , 5 , and 8.

A major interplay occurs between TGF- $\beta$ and BMP signaling, such that cellular responses to one class of cytokine are heavily influenced by co-exposure to the other class. In the kidney, negative regulation of TGF- $\beta 1$ signaling by BMP-7 has emerged as a key anti-fibrotic mechanism. BMP-7 prevents fibrosis and antagonizes the effects of TGF- $\beta 1$ in animal models, including unilateral ureteric obstruction, ${ }^{5}$ nephrotoxic serum nephritis, ${ }^{6}$ collagen IV-alpha3-deficient mice (Alport syndrome), ${ }^{7}$ MRLIpr/Ipr mice (lupus nephritis-like glomerulonephritis), ${ }^{7}$ and nephropathy associated with streptozotocininduced diabetes. ${ }^{8}$ Accordingly, BMP-7 has attracted substantial interest as a potential therapy for chronic kidney disease.

Other BMPs also are expressed in the kidney, but to date they have received surprisingly little attention as potential modifiers of fibro-proliferative disorders. In this issue of The American Journal of Pathology, Dendooven et $\mathrm{al}^{9}$ have examined expression of BMP-6 in the adult murine kidney and the effect of genetic deletion of BMP-6 on renal BMP signaling and response to renal injury. They found BMP-6 expression in the renal cortex, predominantly the tubulo-interstitium. In BMP-6-null mice, they found a modest reduction in intrinsic renal BMP signaling activity and a consequent minor decrease in BMP target gene expression without inherent change in renal histologic appearances or glomerular number. These findings suggest that BMP-6 plays a minor role in renal development, or that its functions are easily covered in this context by functional redundancy from other BMPs such as BMP-7. This is an important difference between BMP-6 and BMP-7, in that BMP-7 null mice show major defects in nephrogenesis. ${ }^{10,11}$

Following unilateral ureteric obstruction, significantly more renal damage was observed in BMP-6-null mice, compared with control animals. The major differences were seen in the tubulo-interstitium of the obstructed kidneys, which in BMP-6-null mice demonstrated increased leukocyte influx and fibrosis. Importantly, these effects occurred despite normal BMP-7 expression and increased BMP-2, BMP-4, and BMP-5 expression, suggesting that while functional redundancy in BMPs may

Accepted for publication December 14, 2010.

Address reprint requests to Donald J. Fraser, M.B., Ch.B., Ph.D., F.R.C.P., Institute of Nephrology, School of Medicine, Cardiff University, Heath Park, Cardiff, CF14 4XN, Wales, United Kingdom. E-mail: fraserdj@ cf.ac.uk. 
allow for normal development and renal function in BMP6 -null animals, functional redundancy in BMPs is not sufficient to protect the adult animal during renal injury.

An interesting question remains regarding the mechanisms by which BMP-6 deficiency augments the scarring response to injury. Dendooven et $\mathrm{al}^{9}$ demonstrate diminished BMP signaling in obstructed kidneys, in the form of decreased phosphorylation of Smads 1, 5, and 8 and enhanced expression of TGF- $\beta$-responsive genes including PAl-1, collagen, and $\alpha$-smooth muscle actin. These changes could be explained by enhanced TGF- $\beta$ responsiveness or by enhanced TGF- $\beta$ synthesis in BMP6 -null kidneys. The authors found no significant alteration in TGF- $\beta$ mRNA, but TGF- $\beta$ is extensively post-transcriptionally regulated, ${ }^{12}$ and thus it remains possible that excessive synthesis of TGF- $\beta$ is contributory in BMP-6 null animals. Perhaps more likely, however, is relative deficiency in combined BMP-6 and BMP-7, which share extensive amino acid homology, receptors, and R-Smads, leading to partial loss of regulation of TGF- $\beta$ signaling by BMPs. BMP-7 inhibits nuclear Smad 3 accumulation in mesangial cells ${ }^{13}$ and specifically limits Smad 3 signaling in proximal tubular cells via maintenance of SnoN expression ${ }^{14}$; it is possible that similar mechanisms underlie the actions of BMP-6 that Dendooven et $\mathrm{al}^{9}$ have uncovered.

Fibro-proliferative disorders are considered to be driven largely by fibroblasts, which are spindle-shaped, motile, contractile cells that respond to pro-fibrotic stimuli by synthesizing and reorganizing extracellular matrix. Fibroblasts may originate from proliferation of local tissue fibroblasts, from circulating bone marrow-derived precursors (fibrocytes), and from resident epithelial cells by epithelial to mesenchymal transition. ${ }^{1}$ Dendooven et $\mathrm{al}^{9}$ have approached the potential role of nonresident fibroblast precursors by studying splenic fibrocytes. They show an increase in spleen-derived myofibroblast progenitor cells in the BMP-6-null animals without apparent incorporation into the kidney. This finding leaves open the question of the cellular origin of fibroblasts in this context, which is a potentially interesting avenue for future study.

Overall, Dendooven et $\mathrm{al}^{9}$ have uncovered what may be a major role for BMP-6 in determining renal response to injury. Future experimental studies in other models will be of great interest, in that they will inform us of the generality of these findings. It also would be interesting to know whether renal physiology and function remain well preserved in aged BMP-6-null animals.

\section{References}

1. Wynn T: Cellular and molecular mechanisms of fibrosis. J Pathol 2008, 214:199-210

2. Border W, Ruoslahti E: Transforming growth factor-beta in disease: the dark side of tissue repair. J Clin Invest 1992, 90:1-7

3. Massague J: How cells read TGF-beta signals. Nat Rev Mol Cell Biol 2000, 1:169-178

4. Ross S, Hill C: How the Smads regulate transcription. Int J Biochem Cell Biol 2008, 40:383-408

5. Morrissey J, Hruska K, Guo G, Wang S, Chen Q, Klahr S: Bone morphogenetic protein-7 improves renal fibrosis and accelerates the return of renal function. J Am Soc Nephrol 2002, 13(Suppl 1):S14S21

6. Zeisberg M, Hanai J, Sugimoto H, Mammoto T, Charytan D, Strutz F, Kalluri R: BMP-7 counteracts TGF-beta1-induced epithelial-to-mesenchymal transition and reverses chronic renal injury. Nat Med 2003, 9:964-968

7. Zeisberg M, Bottiglio C, Kumar N, Maeshima Y, Strutz F, Muller G, Kalluri R: Bone morphogenic protein-7 inhibits progression of chronic renal fibrosis associated with two genetic mouse models. Am J Physiol Renal Physiol 2003, 285:F1060-F1067

8. Sugimoto H, Grahovac G, Zeisberg M, Kalluri R: Renal fibrosis and glomerulosclerosis in a new mouse model of diabetic nephropathy and its regression by bone morphogenic protein-7 and advanced glycation end product inhibitors. Diabetes 2007, 56:1825-1833

9. Dendooven A, van Oostrom O, van der Giezen DM, Leeuwis JW Snijckers C, Joles JA, Robertson EJ, Verhaar MC, Nguyen TQ, Goldschmeding R: Loss of endogenous bone morphogenetic protein-6 (BMP-6) aggravates renal fibrosis. Am J Pathol 2011, 178:1069-1079

10. Luo G, Hofmann C, Bronckers AL, Sohocki M, Bradley A, Karsenty G: BMP-7 is an inducer of nephrogenesis, and is also required for eye development and skeletal patterning. Genes Dev 1995, 9:2808-2820

11. Oxburgh L, Dudley AT, Godin RE, Koonce $\mathrm{CH}$, Islam A, Anderson DC, Bikoff EK, Robertson EJ: BMP4 substitutes for loss of BMP7 during kidney development. Dev Biol 2005, 286:637-646

12. Kim S, Park K, Koeller D, Kim K, Wakefield L, Sporn M, Roberts A: Post-transcriptional regulation of the human transforming growth factor-beta 1 gene. J Biol Chem 1992, 267:13702-13707

13. Wang S, Hirschberg R: Bone morphogenetic protein-7 signals opposing transforming growth factor $\{$ beta\} in mesangial cells. J Biol Chem 2004, 279:23200-23206

14. Luo DD, Phillips A, Fraser D: Bone morphogenetic protein-7 inhibits proximal tubular epithelial cell Smad3 signaling via increased SnoN expression. Am J Pathol 2010, 176:1139-1147 